\title{
A 'FIXAÇÃO' DO PODER: O QUE OS DESASTRES PODEM NOS DIZER SOBRE GESTÃO
}

\author{
Nidhi Srinivas ${ }^{1}$
}

\section{Resumo}

Este artigo discute as respostas a desastres gerenciais contemporâneas. As políticas neo-liberais nas últimas duas décadas tem limitado o alcance (e em alguns casos), a capacidade do estado. Eles têm restringido o que o Estado deve fazer diretamente ao criar espaços de intervenção da sociedade civil. Estas tendências têm afetado profundamente resposta a desastres contemporânea, tais como com os recentes terremotos no Haiti e Chile. Através de uma tríade conceitual eu explico como o poder torna-se "fixo", como as intervenções gerenciais para alívio de desastres ao privar o controle local sobre a direção e a qualidade de alívio. Eu também considerar como tal poder pode ser "não fixado", considerando-se alguns esforços no uso das mídias sociais e políticas de assistência humanitária para aumentar o nível da voz da comunidade na resposta a catastrofes.

Palavras-chave: Gerencialismo; Catástrofes; Poder; Dussel

\section{THE 'FIXING' OF POWER: \\ WHAT DISASTERS CAN TELL US ABOUT MANAGEMENT}

\begin{abstract}
This paper discusses the managerial responses to contemporary disasters. Neo-liberal policies over the past two decades have limited the reach (and in some cases) the capacity of the state. They have restricted what the state should do directly while creating spaces for civil society intervention. These trends have profoundly affected contemporary disaster response, such as with recent earthquakes in Haiti and Chile. Through a conceptual triad I explain how power becomes 'fixed', how managerial interventions to disaster relief deprive local control over the direction and quality of relief. I also consider how such power can be 'unfixed', considering some efforts in the use of social media and humanitarian assistance policies to increase community-level voice in disaster response.
\end{abstract}

\footnotetext{
${ }^{1}$ Milano. The New School of Management and Policy, 72 Fifth Avenue, New York City, 10011, USA. E-mail: srinivan@newschool.edu

Revista Brasileira de Estudos Organizacionais · v. 2, n. 1, p. 58-80, jun.2015, eISSN: 2447-4851 Sociedade Brasileira de Estudos Organizacionais
} 
Keywords: Managerialism; Disasters; Power; Dussel

\section{LA "FIJACIÓN" DEL PODER: LO QUE LOS DESASTRES PUEDEN DECIR DE GESTIÓN}

\section{Resumen}

Este artículo analiza las respuestas a los desastres gerenciales contemporáneas. Las políticas neoliberales de las últimas dos décadas ha limitado el alcance (y en algunos casos), la capacidad del Estado. Ellos han restringido lo que el Estado debe hacer directamente a la creación de espacios de intervención de la sociedad civil. Estas tendencias han afectado profundamente la respuesta contemporánea a los desastres, como con los recientes terremotos en Haití y Chile. A través de una tríada conceptual explico cómo el poder se convierte en "fijo", como las intervenciones de gestión para las operaciones de socorro al privar control local sobre la dirección y la calidad de alivio. También considero cómo ese poder puede ser "no fija", teniendo en cuenta algunos esfuerzos en el uso de políticas de asistencia humanitaria medios sociales y para aumentar el nivel de voz de la comunidad en respuesta a los desastres.

Palabras-clave: Gerencialismo; Desastres; Potencia; Dussel 


\section{Introdução}

.. homens e mulheres de toda camada social podiam ser vistos deitados lado a lado, príncipes e mendigos, damas e camponesas, autoridades do governo e trabalhadores diários, frades e freiras: apiedando-se uns dos outros, ajudando uns aos outros, alegremente compartilhando o que tivessem guardado para se manterem vivos, como se o desastre geral tivesse unido todos os sobreviventes em uma única família.

-- Heinrich von Kleist (1807)

ninguém, ninguém é

cidadão se você for ver a

festa do Pelô

e se você não for pense no

Haiti, reze pelo Haiti

o Haiti é aqui - o Haiti não é aqui

-- Caetano Veloso and Gilberto Gil (1993)

No romance "Terremoto no Chile", dois amantes ainda não casados e seu filho ilegítimo, na cidade de Santiago do Chile, em 1647, são condenados por seus atos. A mulher culpada é levada para a execução, a criança deixada em um orfanato, e o homem, aprisionado. Sem conseguir suportar isso tudo, o homem tenta se enforcar. Porém, o terremoto que subitamente engole a cidade, destruindo grande parte de Santiago, traz uma bênção inesperada. Ele interrompe a tentativa de suicídio do homem, liberta-o da prisão. O casal se reencontra, recupera seu filho, e decide partir para Constitución, no litoral sul do Chile. Conforme descrito na primeira parte, o desastre, de várias maneiras, uniu as pessoas "em uma única família". Porém, a igreja denuncia o desafortunado casal como pecadores, na verdade, aqueles cujas ações pecaminosas levaram ao terremoto. Eles são atacados por uma multidão, e morrem da maneira mais horrível. Ao final desta estória, outro homem, Don Fernando, recupera o filho do casal, apesar de, em troca, ver seu próprio filho ser assassinado pela multidão (que o confundiu com o filho ilegítimo do casal). “... e quando Don Fernando comparou Felipe a Juan, e pensou em como tinha adquirido ambos, ele sentiu quase como se devesse se alegrar" (von KLEIST, 1807). 
O que podemos aprender desta sombria e irônica estória? Talvez o autor, von Kleist, esteja dizendo que há uma cruel piada cósmica em nossas vidas. Uma morte negada aqui é uma morte renovada rapidamente. Mas ele também parece estar dizendo que a sociedade não é capaz de mudar de verdade - até mesmo um desastre que acaba com prédios e, por um momento, une os sobreviventes, não consegue, em última instância, alterar as visões estabelecidas que podem por si sós serem perniciosas e destrutivas.

No dia 12 de janeiro de 2010, um terremoto de 7 pontos destruiu grande parte da capital do Haiti, Porto Príncipe. Logo depois de iniciar meu trabalho como professor na New School, recebi um e-mail de um exaluno meu que estava trabalhando em Porto Príncipe quando começou o terremoto. Parte da mensagem dizia:

Por enquanto, temos gasolina, água etc. Não vi as notícias ainda, mas ouvi falar que os haitianos estão sendo retratados da mesma maneira de sempre - negros pobres, estúpidos, loucos. Por favor, faça o que puder para mudar isso. Hoje, a maioria das pessoas ficou sem comida. A água também acabou na maioria dos lugares. Ouvimos tiros à noite. A comunidade internacional não fez NADA.

Os múltiplos temas tratados no e-mail - o súbito e severo impacto do desastre, os temores de violência generalizada, a frustração com os estereótipos racistas dos haitianos, e a lenta resposta internacional lembraram-me do clássico Tropicália 2, de Caetano Veloso e Gilberto Gil (1993). A canção "Haiti" começa com uma descrição de negros sendo espancados por soldados negros e não tão brancos em uma praça em Salvador, Bahia, onde seus ancestrais haviam sido vendidos como gado. $\mathrm{O}$ refrão, "O Haiti é aqui, o Haiti não é aqui", lembra os brasileiros que, dentro de seu rico país, há muitos "Haitis", zonas de pobreza racializada dentro da riqueza racializada. E, se um país pode ter esses dois extremos, não se pode esperar a proteção e os direitos básicos esperados como membros de um país, como sua comunidade imaginada. Conforme observado pela segunda estrofe, "Ninguém, ninguém é cidadão". Assim, perpetua-se uma elisão, uma amnésia e hipocrisia herdadas, que fortalecem uma tendência a se imaginar como sozinho, sem obrigações ou, em um pacto social, como um agente livre.

Cerca de um mês depois, em 27 de fevereiro de 2010, um terremoto de 8.8 pontos atingiu o Chile, devastando Constitución (o porto para onde fugia o desafortunado casal na estória de Kleist). A cobertura imediata da mídia condenou a resposta lenta e militarizada, e os comentaristas questionaram a maneira como as vítimas do desastre eram representadas na mídia, e se quase três décadas de políticas neoliberais tinham 
exacerbado o desastre, repetindo temas da cobertura do terremoto no Haiti. O romance de Kleist, o e-mail com o testemunho do meu ex-aluno, e a canção de Gil e Caetano, todos me lembraram de dois fatos contraditórios. Mesmo nas situações mais extremas que são os desastres, há altruísmo. Mas tal altruísmo parece incapaz de superar os códigos sociais que condicionam a resposta e a recuperação após tais eventos. Em tais situações, fazem-se afirmações que demonstram não apenas quem queremos ser, mas também quem nós realmente somos, afirmações de pertencimento e inclusão, de cidadania. Elas suscitam questões importantes de comportamento social durante desastres, como canalizá-lo, e os meios de reforçar a resiliência de comunidades afetadas.

Esses dois graves eventos causaram terríveis perdas de vidas, arrasando ou danificando paisagens urbanas reconhecíveis, arrancando tipos de vida de suas raízes. Mas eles também mostraram respostas a desastres incorporadas a padrões distintos de capitalismo e gestão. Estreitamente ligado ao capitalismo de desastre, as políticas do capitalismo neoliberal, estava seu partícipe secreto, o gerencialismo de desastre, ideologias de especialidade e intervenção profissionais. $\mathrm{Na}$ verdade, ambos os padrões enfraqueceram a capacidade e resiliência locais de resistência ao inesperado. $O$ presente trabalho foi escrito como uma reflexão sobre esses dois terremotos. Esses desastres, que ocorreram um após o outro, revelaram controvérsias agudas acerca da gestão de resposta a desastres, especialmente na maneira como organizações não governamentais ofereceram ajuda humanitária e atenderam adequadamente às necessidades das comunidades afetadas.

O trabalho divide-se em quatro seções. A primeira seção nomeia os desastres em termos de dois referentes conceituais, o capitalismo de desastre e o gerencialismo de desastre. Pelas duas últimas décadas, as políticas neoliberais limitaram o alcance e (em alguns casos) a capacidade do Estado. Elas restringiram o que o Estado deveria fazer diretamente enquanto criavam espaços para a intervenção da sociedade civil. Eu refiz essas trajetórias por meio de dois corpos de literatura, a construção social do desastre e os estudos de desenvolvimento crítico, respectivamente. A segunda seção descreve a resposta ao desastre nos terremotos recentes. Ambos os terremotos (Haiti e Chile) ocorreram em um contexto de políticas neoliberais, e a resposta ao desastre foi militarizada, privatizada e sobregeneralizada. A terceira seção estuda as mudanças de poder que ocorrem durante a resposta a desastres, partindo daqueles que vivenciam o desastre e enfrentam seus custos e chegando àqueles que os buscam e alegam tê-los ajudado. Eu apresento uma tríade conceitual para explicar uma "fixação" do poder, de como as intervenções gerenciais na ajuda humanitária excluem o controle local em detrimento da direção e da qualidade da ajuda. A seção final explora como esse poder pode ser "desafixado", considerando alguns esforços no uso de mídias sociais e 
políticas de assistência humanitária a fim de aumentar a voz da comunidade na resposta a desastres.

\section{Dois Referentes Conceituais para Desastres}

Há uma convergência entre os aspectos destrutivos do capitalismo e a maneira como os desastres contemporâneos oferecem oportunidades de promover a geração de capital e os lucros. Essa convergência é chamada por Naomi Klein (2005) de "capitalismo de desastre", um termo que desde então tornou-se linguajar comum. "Certamente parece que porções cada vez maiores do globo estão em ativa reconstrução: sendo reconstruídas por um governo paralelo composto de uma casta familiar de empresas de consultoria com fins lucrativos, empresas de engenharia, mega-ONGs, órgãos de assistência governamentais e da ONU, e instituições financeiras internacionais" (Klein, 2005).

O capitalismo de desastre nomeia duas características: a primeira são os desastres criados pelo próprio capitalismo neoliberal. Esforços abruptos, geralmente autoritários, de reduzir as obrigações do Estado a fim de liberar as forças de mercado têm deixado as sociedades mais expostas ao inesperado, impedindo o fortalecimento das condições necessárias à resistência a alterações devastadoras inesperadas. A redução do Estado sob a rubrica da eficiência e concorrência tornou-se parte de um pacote de reformas que fortaleceram o papel do mercado na suposição de que ele é melhor que o Estado para coordenar a economia e a sociedade (GLEDHILL, 2004; HARVEY, 2007; MIROWSKI, 2009; TURNER, 2008). Nesse sentido, o capitalismo neoliberal aumenta o escopo dos lucros de mercado, mas faz isso às custas das comunidades e de sua própria capacidade de resistir ao impacto dos desastres.

A segunda característica são as oportunidades de enriquecimento que os desastres oferecem ao capital privado. Sejam organizações não governamentais (ONGs), órgãos de assistência ou empresas comerciais, agentes privados usam os desastres como um meio de renda. Klein (2005) descreve o Furação Mitch, de 1985, com um precursor desta tendência, permitindo a venda dos investimentos do Estado em aeroportos, estradas e estradas-de-ferro de Honduras. Os desastres na era neoliberal permitiram lucros por meio da intensa privatização, sejam por meio de patrimônio estatal comprado a baixos preços ou subcontratos lucrativos. O tsunami do oceano Índico em 2004, as crises alimentares enfrentadas no Haiti no mesmo ano, e o furacão Katrina em Nova Orleans em 2005, todos ofereceram esse tipo de oportunidades para intervenções de mercado que enriqueceram investidores privados (SCHULLER, 2008). Nesse sentido, o capitalismo de desastre nomeia uma oportunidade produtiva, uma fonte de retorno para os investidores. 
O livro original de Klein sobre o capitalismo de desastre delineia uma afinidade eletiva entre governos autoritários, políticas econômicas neoliberais, violações dramáticas dos direitos humanos, esferas públicas truncadas e a naturalização de ações privatizadas. Um bom exemplo é o Chile sob os vinte anos da ditadura Pinochet - ele mostra todas essas características. Klein segue descrevendo o capitalismo neoliberal em termos de terapia de choque; a analogia que ela faz é a de pacientes que levam choques no intuito de serem forçados a obedecer, independentemente das doenças mentais que os aflijam. De maneira semelhante, as mudanças sociais do neoliberalismo são possibilitadas por meio da construção social da exigência, um sentido generalizado de ameaça, de desgraça iminente, e a necessidade, portanto, de certas formas de mudança econômica e política. Mas a dificuldade de tal descrição é óbvia - ela combina fenômenos sociais distintos sem explicar as ligações causais entre eles. Aos convertidos, ela certamente fala dos perigos da economia neoliberal. Mas a falta de vontade de se firmar sobre os aspectos específicos da resposta a desastres e reabilitação que estão em questão, e a vaga reunião de tendências perturbadoras e perniciosas podem de fato confundir o julgamento sobre o que exatamente está em questão na resposta a desastres, o que fazer a respeito disso, e o que está sendo feito a respeito disso. $\mathrm{O}$ restante do trabalho descreve os aspectos específicos da resposta a desastres e apresenta respostas encorajadoras que constituem uma resistência incipiente às tendências neoliberais.

As discussões do capitalismo de desastre ficam mais bem situadas dentro de uma literatura mais ampla acerca da sociologia de desastres. Clarke (2005) argumenta que a maneira como funcionam as políticas sociais, instituições locais e sistemas governamentais predominantes moldam significativamente a resposta a desastres. Nesse sentido, alguns desastres naturais são desastrosos menos por causa de sua qualidade inesperada e destrutiva, e mais por causa da falta sistemática de preparação gerada pelas políticas governamentais existentes. Por exemplo, eles são "resultado de falhas estruturais; da inabilidade ou falta de vontade do governo e das indústrias em fornecer financiamento e treinamento adequado onde era necessário; da falta de recursos para os órgãos de gestão de emergências; da atenção inadequada a mitigação, preparação, resposta e recuperação de desastres" (Rodríguez e Barnshaw, 2006). Um evento desencadeante (o terremoto) gera um conjunto de respostas sociais - e são essas respostas que constituem grande parte da qualidade percebida do próprio desastre. Nesse sentido, o capitalismo de desastre é mais bem entendido como condições sociais específicas geradas pelas políticas neoliberais que moldam o impacto do desastre, da resposta e da reabilitação.

Grande parte das críticas a essas políticas gira em torno da privatização. Os serviços estatais privatizados podem excluir a cobertura para esses serviços (por exemplo, ao aumentar os preços de tais serviços), 
bem como a qualidade desses serviços (à medida em que os órgãos estatais deixam de monitorá-los ou de claramente impor requisitos de qualidade nos contratos). Eles também podem retirar os direitos daqueles em localidades afetadas durante a resposta ao desastre, transferindo a responsabilidade para longe das autoridades eleitas em direção aos interesses privados, tomando decisões fora de suas mãos. Mas, possivelmente, o aspecto que define o capitalismo de desastre não é a privatização, mas a mercantilização. Enquanto a privatização é a transferência de controle da coordenação social para atores privados (sejam empresariais ou não governamentais), a mercantilização é o crescimento dos valores de mercado dentro das instituições e interações sociais do dia a dia.

A privatização é o aspecto visível das políticas neoliberais, em que as funções do governo são relegadas às forças de mercado ou vendidas a empresas privadas. Linhas aéreas governamentais são vendidas. Creches ou asilos são subcontratados. A mercantilização é o aspecto menos visível do neoliberalismo, a naturalização da ideologia de livre mercado. Os cidadãos não mais esperam que o Estado forneça proteção, mas recorrem a agentes privados para tal. Não à polícia, mas a empresas de segurança privadas. Não às escolas públicas, mas às privadas. O papel do Estado torna-se o de vender contratos de seus serviços vitais para interesses privados que não são controlados com segurança para o interesse público. É por isso que o neoliberalismo não é apenas um conjunto de políticas amigáveis ao mercado, mas, fundamentalmente, uma ideologia, onde as liberdades do mercado ganham precedência sobre os direitos e expectativas sociais, por meio da instituição e estabilização de valores de mercado em todas as transações sociais. A expectativa é que a liberdade de mercado oferecida (movimento absolutamente livre do capital, para comprar e consumir) é superior à liberdade social oferecida por um Estado intervencionista que garante direitos básicos (GLEDHILL, 2004; MIROWSKI, 2009).

Um aspecto essencial da resposta a desastres são os papéis esperados de organizações privadas que lidam com o impacto imediato do desastre em termos de serviços de saúde e sociais, bem como suas abordagens para reconstruir e reabilitar os locais afetados. Nesse sentido, o capitalismo de desastre privilegia formas particulares de organização e gestão. Especificamente, a expectativa é que iniciativas de mercado privado serão correspondidas por iniciativas sociais privadas, no atendimento às exigências de desastres. Assim, a resposta ao terremoto envolve ONGs e empreiteiros privados, ao invés de ministros de Estado ou grupos comunitários locais. Acompanhando este viés organizacional está o foco em uma forma particular de gestão, aquela baseada em conhecimento especializado reconhecido, reconhecimento de profissionais por grupos de especialistas privados, tais como engenheiros sanitários, agrimensores, gerentes e médicos. Esse tipo de conhecimento especializado, buscando 
uma intervenção por parte daqueles com especialização reconhecida, é o gerencialismo precisamente nos termos usados por Entman (1993) e Parker (2002), o do sistema de crenças que privilegiam os papéis de especialistas certificados, equipados com habilidades analíticas e vocabulário conceitual, na coordenação de sistemas complexos, em nome de seus usuários e membros. O capitalismo de desastre precisa de sua sombra, que eu chamo de gerencialismo de desastre.

O gerencialismo de desastre, junto do capitalismo de desastre, significa que aqueles afetados por desastres, são duplamente atingidos. Eles não apenas suportam o desastre, mas também o desempoderamento inerente às maneiras como a ajuda é oferecida, a reabilitação é fornecida, e a reconstrução, prevista. Da mesma forma como o capitalismo de desastre descreve as oportunidades de lucro e a privatização oferecida pelos desastres, de como eventos desencadeantes são exacerbados por fatores sociais para se tornarem um desastre, o gerencialismo de desastre descreve a afinidade eletiva de tais esforços com formas de especialização incorporadas aos procedimentos, processos e estruturas que excluem aqueles que sofrem com o desastre do controle dos meios de melhorar sua situação e, assim, empoderar a si mesmos.

\section{Os Terremotos no Haiti e no Chile}

Dois terremotos: Porto Príncipe (7.0; 3 milhões de pessoas afetadas; janeiro de 2010), Constituición (8.8; 2 milhões afetados; fevereiro de 2010). $\mathrm{O}$ que eles têm em comum? Vale a pena notar a grande diferença entre esses países, pois o Haiti permanece como um dos países mais pobres do hemisfério ocidental, enquanto o Chile é um país rico, e não apenas quando comparado ao Haiti. Também é importante notar que o impacto do terremoto em vidas perdidas foi maior em um nível mais baixo da escala Richter em Porto Príncipe devido, em parte, à ausência de normas de construção que foram seguidas em Constitución.

Contudo, apesar dessas diferenças reais, há algumas semelhanças impressionantes na resposta aos desastres. Nesta seção, descrevo essas semelhanças e argumento que, enquanto esses terremotos recentes foram "naturais", algo que ninguém poderia ter evitado, totalmente imprevisíveis, eles também foram definidos e encenados socialmente. Esta seção caracteriza os esforços de ajuda humanitária como militarizados, privatizados e "sobredeterminados". Porém, antes disso, vale notar que o contexto social em que ambos os desastres ocorreram foi moldado pelas políticas neoliberais e suas consequências. No Haiti, as políticas de livre mercado tinham levado a um recuo da produção nacional de alimentos, e a uma dependência de importações subsidiadas ${ }^{2}$. No Chile, o impacto foi

\footnotetext{
2 http:/ / english.aljazeera.net/ focus/2010/01/20101196265844450.html
} 
agravado pela desigualdade urbana, levando os moradores de algumas áreas a saquear supermercados em busca de comida.

Sabe-se muito bem que a resposta ao terremoto no Haiti foi altamente militarizada. A força militar pode ser necessária para uma resposta rápida a uma destruição de tal escala. Mas vale a pena considerar como tal força militar foi usada. Os Estados Unidos assumiram o comando imediato do aeroporto em Porto Príncipe, mas os primeiros carregamentos de ajuda humanitária chegaram apenas dois dias após o terremoto. A prioridade de pousos no aeroporto era para tropas americanas, não para voos com suprimentos vitais. " 'Comandar e controlar' acabaram se tornando as palavras-chave. Os militares americanos fizeram o que os militares americanos fazem. Como um gigante temeroso e de raciocínio lento, eles construíram um muro em volta deles mesmos, comandando o aeroporto de Porto Príncipe e construindo uma mini-Zona Verde" ${ }^{3}$. Inicialmente, a ajuda humanitária foi distribuída com segurança reforçada, o que, às vezes, impedia que aqueles que buscavam auxílio acabassem realmente recebendo-o. Pior, as iniciativas bem-intencionadas de toda parte do mundo de resgatar os que estavam presos nos destroços de prédios derrubados foram dificultadas e desestimuladas pelo foco militar. A resposta no Chile também foi altamente militarizada. A primeira presença estatal significativa na cidade de Constitución era o exército. Quando o exército chegou, a cidade tinha sido isolada do mundo, e sem ajuda, havia quatro dias. (as áreas em torno da região costeira circundante passaram muito mais tempo - em alguns casos, duas semanas - para receber ajuda). Em tais circunstâncias, não é de surpreender que aqueles que esperavam por ajuda, desesperados por comida, tenham arrombado mercadinhos para encontrar o que podiam. E, assim, a imposição de ordem coercitiva foi ligada a um imperativo como no Haiti, de parar os "saques". A ordem pública foi ligada à proteção da propriedade privada, em uma época em que a necessidade de compartilhar parte dessa propriedade (comida) era urgente. As ênfases em ambos os casos eram claras - segurança acima da ajuda, ordem pública em termos de propriedade privada.

Outro aspecto comum de ambos os desastres foi que a resposta foi significativamente privatizada. A ajuda foi direcionada esmagadoramente por meio de agências de assistência, ONGs e empreiteiras. Ao invés de ser distribuída diretamente pelo Estado, e pelos representantes das localidades, a ajuda foi delegada a intermediários não estatais que demonstravam pouca motivação para se engajar e trabalhar de verdade com os representantes de níveis locais. Dessa forma, em ambos os lados da resposta de ajuda, não havia um esforço para gerar uma noção de 'público' e de interesse público, mas, ao invés disso, de buscar interesses privados individuais. Às vezes, esses interesses eram não apenas

3 http://www.slate.com/id/2242078/ 
privados, mas também corruptos. "Muitos dos programas de ajuda governamental e ONGs menores são administradas por pessoas capazes, ativas e desinteressadas, mas outras, geralmente as maiores, são pouco mais que quadrilhas, altamente rentáveis para os que as administram" 4 . Isso levou Noam Chomsky a afirmar que "a ajuda está vindo - temos que mostrar que somos pessoas boas e tudo mais. Mas a ajuda tem que ir para as organizações populares haitianas. Não para empreiteiras, não para ONGs - para organizações populares haitianas, e elas é que devem decidir o que fazer com essa ajuda" (citado em BHATT, 2010).

Como parte do esforço de privatização, não havia um esforço substantivo para se engajar com os grupos comunitários locais, nem para se pensar em parcerias que fortaleceriam as respostas da comunidade ao desastre (BHATT, 2010). Isso era aparente não apenas no Haiti, mas, em um sentido levemente diferente, também no Chile. Comentaristas como Ariel Dorfman argumentaram que o Chile tinha se tornado uma "sociedade mais egocêntrica e individualista onde, ao invés de uma visão de justiça social para todos, os cidadãos estão, na maioria das vezes, engajados em uma corrida frenética em direção a um consumo cada vez maior, e sujeitos, obviamente, ao estresse e anomia" 5 . Ou seja, o legado das políticas neoliberais foi a naturalização do interesse individual próprio, às custas da segurança e solidariedade comunitárias.

Associada a esse problema estava a prevalência de grandes supermercados nas cidades atingidas pelo terremoto; as reformas de mercado permitiram que os grandes supermercados se expandissem nas áreas urbanas, reduzindo o número de pequenos supermercados, causando uma escassez peculiar de opções de varejo. Agora imagine o que isso significa para alguém em busca de comida depois do terremoto - há poucas lojas locais a se buscar, seja por comida ou remédios. Os supermercados impessoais que substituíram as lojas menores estavam fechados, e não dispunham dos meios flexíveis para responder às necessidades dos clientes à sua volta. Dessa maneira, as políticas neoliberais contribuíam não apenas para a cultura da privatização, mas também moldavam e refletiam a polarização social. A falta de flexibilidade dos supermercados locais foi resultado da desigualdade social, uma sociedade onde conglomerados cresceram às custas de pequenas lojas, sem acesso igualitário e flexível. "A frustação popular explodiu conforme multidões desciam para o centro comercial, levando de tudo, não apenas comida dos supermercados, mas também calçados, roupas, TVs de plasma e telefones celulares. Isso não era um simples saque, mas o acerto de contas com um sistema econômico que dita que só as posses e as commodities importam" ${ }^{\prime \prime}$. Portanto, a privatização refletiu-

\footnotetext{
${ }^{4} \mathrm{http}: / /$ www.independent.co.uk/opinion/commentators/ patrick-cockburn-the-us-is-failing-haiti-ndashagain-1869539.html

5 http://www.cnn.com/2010/OPINION/03/02/dorfman.chile.earthquake.unity/index.html

${ }^{6} \mathrm{http}: / /$ www.countercurrents.org/burbach090310.htm
} 
se em ambos os desastres em termos da ajuda sendo direcionada por meio de agências privadas, e a falta de uma resposta rápida do governo ou um engajamento substantivo com as comunidades locais.

Finalmente, ambos os desastres foram representados por meio de relatos sobredeterminados. Com isso, quero dizer que o comportamento dos que sofreram durante esses desastres foi explicado apontando-se seu caráter social como a principal explicação. Houve um esforço significativo para sobregeneralizar as características sociais das vítimas (raça, classe), de forma que suas ações não merecessem muita discussão pública, mas supondo que se adequassem a um padrão inerente e profundo. As imagens de haitianos perigosos, indisciplinados e incivilizados foram mobilizadas para justificar uma resposta militarizada. Um observador descreveu isso de maneira um tanto cáustica como uma versão ideológica dos Doldrums, referindo-se à região de movimento lento no mar do Caribe onde o lixo permanece na superfície devido à movimentação lenta das águas. "Primeiramente, não é composto por fragmentos materiais, mas por abstrações, aparições estranhas que não envenenam os peixes nem sujam as praias, mas envenenam as mentes e sujam novas e arrojadas políticas com o detrito tóxico da antiga ignorância, histeria e crenças irracionais. É um lugar onde as antigas difamações racistas ainda perduram, levando os políticos americanos à distração e à Bíblia"7. De maneira semelhante, no Chile, as imagens de saqueadores perigosos foram dominantes, mas motivadas agora por classe, não por raça. Os pobres estavam roubando de lojas fechadas e, por isso, a força militar era necessária para evitá-los e proteger os abastados. Através dessas descrições, aqueles que estavam sofrendo as piores consequências do desastre ficam situados dentro de representações irredutíveis e inflexíveis moldadas pelas desigualdades dominantes de raça e classe. Uma vez situados dessa forma (os perigosos pobres chilenos, os haitianos primitivos), eles ficam presos a representações mobilizadas na mídia, justificando os esforços para impor soluções militarizadas e privatizadas.

$\mathrm{Na}$ próxima seção, argumentarei que essas características descritas acima, militarização, privatização e sobredeterminação, geraram uma posição particular em relação à gestão da resposta ao desastre.

\section{A Fixação de Poder em Desastres}

Três conceitos são úteis para a compreensão do modo como a resposta a desastres é gerenciada: conhecimento, ética e poder (SRINIVAS, 2009). Essa tríade conceitual oferece um meio útil para se entender o tipo de intervenção gerencial buscada na ajuda aos desastres.

\footnotetext{
7 http://www.counterpunch.org/maxwell01252010.html
} 
Quadro 1 - Uma tríade conceitual

\begin{tabular}{|l|l|l|l|}
\hline Trajetória & Conhecimento & Ética & \multicolumn{1}{|c|}{ Poder } \\
\hline $\begin{array}{l}\text { Gerencialismo } \\
\text { de Desastre }\end{array}$ & Performativo & Sobredeterminado & Potestas \\
\hline
\end{tabular}

Imagine um ambiente em que o poder existe em todos os lugares e com todas as pessoas. Agora imagine que nós nos asseguramos que tal poder não existe em lugar algum e com pessoa alguma, mas está concentrado em alguns lugares e pessoas. É nesse sentido que o poder na ajuda aos desastres torna-se fixo, que as agências de ajuda, os departamentos governamentais, as ONGs, todos adquirem poder sobre os outros, que eles tentam ajudar, os objetos da ajuda. Porém - e isso é crucial - eles são capazes de fazer isso devido a um contexto particular, onde o papel do Estado é diminuído e o do capital e iniciativa privada são ampliados.

Tal contexto busca uma forma particular de conhecimento, uma que permita que essas organizações utilizem especialistas certificados. $O$ restante desta seção apresenta uma tríade conceitual para entender melhor esta fixação de poder.

\section{Conhecimento}

O conhecimento gerencial serve, no mínimo, a dois propósitos amplos. $\mathrm{Na}$ maioria das vezes, os estudantes de administração buscam ambos os propósitos, mas podem não estar cientes de que fazem isso. $\mathrm{O}$ mais óbvio deles é um propósito performativo ou instrumental (FOURNIER; GREY, 2000, p. 17), onde o conhecimento é necessário para se atingir objetivos, para aprimorar a eficiência produtiva. Listas de verificação e procedimentos, "melhores práticas", sistemas de monitoramento e aparato relacionado para controlar e garantir o progresso são os aspectos mais visíveis desse tipo de conhecimento. Mas o conhecimento também serve a outro propósito: ele nos ajuda a encontrarmos a nós mesmos, muda a maneira como vemos o mundo à nossa volta, ajuda-nos a conhecer. Este é o propósito subjetivo ou ético, de esclarecer identidades, definir a si mesmo e à sua relação com o mundo social (WILLMOTT, 2003). De fato, até mesmo o conhecimento performativo, como aquele gerado para administrar melhor as ONGs, tem realmente um efeito na identidade própria. Mas esse propósito de conhecimento é aspiracional, um desejo de se atingir uma meta que seja fundamental para o próprio ser, que molde a agência. Enquanto tal conhecimento pode e, de fato, tem um fim instrumental, não é essa instrumentalidade que é crucial na compreensão do seu propósito, mas o foco no empoderamento. Nesse sentido, imagine o propósito do conhecimento gerencial em termos do desejo de um aluno 
graduado na faculdade de administração por um emprego estável. Agora contraste esse sentido de propósito descrito por uma mulher do Malaui, que estuda no Barefoot College (Faculdade dos Pés Descalços) em Tilônia, no Rajastão, Índia, para treinamento na montagem de painéis solares, que deseje voltar à sua vila e oferecer uma fonte de eletricidade estável ${ }^{8}$. Em termos dos seus desejos, as pessoas nesses exemplos buscam, respectivamente, propósitos instrumentais ou aspiracionais, embora, obviamente, isso não impeça o oposto, isto é, que o graduado em administração tenha uma aspiração e que a estudante do Barefoot busque unicamente um emprego.

\section{Ética}

A segunda parte da tríade é a ética, e, com isso, quero dizer um conjunto de princípios que orientam nossas ações. "A ética é um trabalho de autoformação no qual o sujeito,por assim dizer, sujeita a si próprio a certas práticas que processualmente visam a um certo telos" (CRITCHLEY, 2007, p. 41; PARFITT, 2002). Chamar esses princípios "morais" pode dar a entender que eles são, de alguma forma, corretos, mas, ao invés disso, eles vinculam o "eu" a "alguma concepção do bom" (CRITCHLEY, 2007, p. 39). Em resumo, há algumas ações que não faremos por causa de nossa orientação ética, e algumas que faremos por essa razão. A ética, nesse sentido, está relacionada à subjetividade, a quem queremos ser, à identidade que buscamos baseados em valores que compartilhamos e que orientam nossas ações na direção dos fins e meios escolhidos, das respostas ao mundo e como esse mundo nos afeta.

De maneira ampla, podemos assumir duas posições nesses princípios éticos. Uma maneira de expressar esse princípio moral é a extrema clareza, onde identificamos o que é bom e mal com obediência escrupulosa mas rígida a princípios fundamentais. Por exemplo, eu poderia declarar que as corporações multinacionais são más, até mesmo perversas. Então, eu indicaria uma história da empresa United Fruit na Guatemala, talvez até relembrasse o poema de Pablo Neruda na incrível coletânea Canto General, na qual ele descreve como a empresa United Fruit "arrasando el café y las frutas/ en sus barcos que deslizaron/ como bandejas el tesoro/de nuestras tierras sumergidas". 9

Digamos que um princípio seja ilustrado dessa maneira: o capital estrangeiro investido em um ambiente nacional tem consequências terríveis no mundo em termos de dignidade humana, economia local e autonomia política. Eu chamarei tal declaração de sobredeterminada. É

\footnotetext{
${ }^{8}$ Baseado em dados coletados durante minha visita e minhas entrevistas, 16 de fevereiro de 2009.

9 "amontoaram café e frutas em navios/ que puseram ao mar como/ bandejas sobrecarregadas com os tesouros/de nossas terras submersas" (NERUDA, 1991).
} 
sobredeterminada no sentido em que há uma ênfase excessiva no sujeito (a multinacional) sem esclarecer adequadamente que sujeito é esse realmente (a multinacional é sempre má da mesma maneira, por exemplo?). As formulações sobredeterminadas encerram a discussão. Nós investimos significado excessivo no termo 'corporação multinacional', presumindo que todas as organizações assim nomeadas comportam-se de maneira similar, e pouquíssimo significado no termo residual "mundo". Encerramos o debate sobre os papéis e consequências das multinacionais, e assim por diante. Ao tornar o sujeito ativo (a força moldando a história), também tornamos o objeto passivo (as pessoas deste mundo tornaram-se espectador e vítima dessa história). Investimentos semelhantes de significados excessivos ocorrem com "ONGs", "desastres", "saqueadores" ou "a comunidade".

Essa maneira de expressar o princípio ético pode ser contrastada com outra, que procede não por declaração rígida de um princípio fundamental, mas, ao invés disso, por uma expressão refinada de uma noção autocompreendida do bom. Essa seria uma abordagem que deixa em aberto um princípio e pede diferentes opiniões, na esperança de gerar uma conversação. Chamarei essa abordagem de "reflexiva". Um exemplo ligado ao anterior seria se perguntar quais as consequências do capital multinacional investido em um ambiente nacional. A resposta pode ser que há consequências negativas e positivas: que, para cada United Fruit, há uma Unilever, sendo que esta última simplesmente buscou ganhar dinheiro por meio de tecnologia e produtos externos, e não viu qualquer razão para interferir com o poder local (pois o poder local já estava a seu favor). $\mathrm{Ou}$, que a pergunta deveria ser contrastada com as consequências do capital nacional - uma multinacional seria naturalmente mais perversa do que um concorrente local? Além disso, no mundo em que vivemos atualmente, podemos separar apropriadamente o capital estrangeiro do nacional? E, se não podemos, o que isso nos diz acerca do sujeito putativo desta formulação, a corporação multinacional? Dessas maneiras diferentes, uma posição ética reflexiva busca manter as questões abertas, permitir alguma discussão, questionamento ativo, e a inquietação no escopo da questão ética, e os princípios em debate. Uma implicação ética urgente é deixar as questões abertas. Ou seja, criar um processo de interação e comunicação que seja sensível aos custos de se encerrar qualquer questão que esteja sendo discutida. $\mathrm{O}$ fechamento epistêmico, o ato de definir algo ao ponto em que não seja questionado de maneira alguma, é, a partir desta perspectiva, antiético.

Poder

Finalmente, podemos distinguir duas maneiras de entender o poder, segundo Dussell (2009). Uma maneira é olhar para o poder que reside em cada um de nós. Qualquer um que já tenha se exercitado, corrido, remado 
em um caiaque ou andado de bicicleta saberá o valor da atividade física. A força do músculo no corpo, reduzida por uma substância inflexível (o barco, a bicicleta, a milha), pode causar uma sensação de poder. Isso pode nos libertar (em certo sentido). Ou pense em um concerto, em ser tomado pela música, sua alma, corpo e vontade em união com o que você ouve. Isso também é uma sensação de poder. É nesses sentidos que este tipo de poder pode ser descrito como potentia, aquilo que está dentro de nós, um potencial.

Agora, contraste essa noção de poder com aquele da autoridade formal, por exemplo, o de um membro de conselho, governador ou presidente. $\mathrm{Ou}$ o de um gerente ou administrador de uma ONG. Ou um líder comunitário. Nesses exemplos, também estamos testemunhando outro aspecto do poder, aquele em que esse potencial é delegado, onde grupos de pessoas distribuem seu poder inerente a uma pessoa que os representa, na esperança de que esta seja uma maneira mais eficiente de influenciar as questões. Por exemplo, um líder representa um grupo com visões diferentes e conflitantes acerca do bem comum. Mesmo assim, ele deve unir os membros de maneira suficientemente efetiva a fim de atingir ao menos alguma aparência dessas visões. É esta noção de poder que podemos chamar de potestas, o poder que é delegado por um povo àqueles que o servirão.

\section{Gerencialismo de desastre}

Há uma afinidade eletiva entre capitalismo neoliberal e gerencialismo neoliberal. "Genrencialismo" é um termo comumente usado para denotar uma trajetória particular de poder, onde se espera que aqueles treinados nas técnicas de organização formal sejam capazes de resolver problemas sociais persistentes (PARKER, 2002; GREY, 1996, 2005). Considere tal trajetória de poder nos termos da tríade conceitual que acabamos de descrever. O foco aqui está nos especialistas certificados, aqueles confiáveis em termos de projetar tipos específicos de sistemas de monitoramento, que possam permitir os resultados buscados. Claramente, o conhecimento é performativo - tem um propósito, um certo fim. Ele é aspiracional? Ao ponto em que imaginamos o conhecimento como liberador, não, esta trajetória não busca tal fim. Está focada no controle, no uso de hierarquias formalizadas a fim de garantir resultados considerados necessários e desejáveis para o progresso social.

O que se pode dizer eticamente sobre tal trajetória? Ela não busca deixar as matérias irresolutas, abertas. De fato, é importante destacar o fechamento, já que ele proporciona a decisão, delega tarefas e garante os resultados ora identificados. Portanto, esta é uma posição ética sobredeterminada. Ela define em excesso a fim de não passar muito tempo divagando e debatendo o significado do que está sendo decidido. Mais especificamente, os procedimentos são criados, as tarefas são projetadas 
de forma que o debate seja desnecessário, até mesmo um obstáculo. O que é importante, ao invés disso, é agir, e fazer isso com confiança, por fechamento. Ao ajudar a fazer isso, esta posição ética é fortalecida pelo foco performativo. O que pode ser mais confiável do que saber que algo é verdadeiro, e, se há um especialista certificado como tal, certamente aquele conhecimento é verdadeiro? Dessa maneira, a tendência a se sobredeterminar os sujeitos e objetos de agência é bem correspondida pelos imperativos performativos buscados de conhecimento certificado.

$O$ poder gerencialista busca maneiras de controlar esferas da sociedade, por meio de organizações de trabalho, sejam privadas, estatais ou, mais recentemente, ONGs em busca de progresso social. Em todas essas organizações, a forma de autoridade e poder buscada é delegada, mediada. Não são os trabalhadores, nem as autoridades oficiais, nem os moradores dos vilarejos, sequer os funcionários das ONGs que finalmente exercem o poder. Todos eles detêm, em diferentes medidas, formas de poder delegado, o poder de - a fim de - poder sobre. O poder dos cidadãos para o executivo, dos acionistas para os diretores, do governo para as ONGs, a fim de reduzir o desemprego, aumentar os lucros, prestar serviços sociais, requer poder sobre os cidadãos, sobre outros acionistas (cidadãos, na verdade) e clientes (destinatários dos serviços). E, dessa maneira, o gerencialismo tanto permite quanto estimula a potestas, formas de poder delegado para se alcançar progresso social. Contudo, ele faz isso de maneira sobredeterminada e performativa, e isso diminui a potentas.

Enquanto a discussão do gerencialismo dentro dos estudos de gestão crítica revelam bem a afinidade entre um conhecimento certificado (tal qual o oferecido por uma faculdade de administração reconhecida pela AACSB ${ }^{10}$ ), com poder profissional (tal qual o de um aluno formado em administração por uma faculdade de administração reconhecida pela AACSB) (Grey 2005), ela não suscita suficientemente questões sobre o que uma discussão de gerencialismo constitui em termos de uma interpretação de conhecimento, ética e poder. Geralmente, a discussão relega a uma crítica somente do poder profissional, sem uma avaliação suficiente da eficácia relacionada, de se estabelecer bases de conhecimento, e alternativas que ofereçam modalidades de ética e poder. A seção seguinte promove essa discussão, considerando práticas e políticas atuais que oferecem respostas alternativas aos desastres, e alternativas ao gerencialismo de desastre.

\section{Alternativas ${ }^{11}$}

\footnotetext{
10 N. do T.: AACSB: The Association to Advance Collegiate Schools of Business, uma organização global sem fins lucrativos de instituições educacionais, empresas e outras entidades que se dedicam ao avanço da educação em administração (http://www.aacsb.edu/en/about/).

${ }^{11}$ Esta seção baseia-se enormemente em Srinivas (2010).
} 
Esta seção começa descrevendo duas amplas formas de resistência às políticas neoliberais contemporâneas: a desmercantilização e a remercantilização. Em seguida, eu descrevo alternativas ao gerencialismo de desastre que demonstram um maior compromisso à resposta de nível local e à capacidade comunitária, que fortalecem os atores comunitários e sua experiência e especialidades locais.

Essas respostas giram em torno da desmercantilização, na qual os atores da comunidade tentam conscientemente se afastar dos valores de mercado; ou da remercantilização, na qual o nível comunitário estrutura as transações comerciais para que permaneçam dentro da localidade, ou menos dependentes do comércio regional e global. Ambas as estratégias fortalecem a resposta da comunidade a desastres, oferecendo formas de especialização que complementam as matrizes profissionais disponíveis para intervenção.

A desmercantilização é uma forma de evitar a mercantilização de bens e serviços. Por exemplo, o Centro Indígena de Capacitación Integral (Cideci), em San Cristóbal de las Casas, em Chiapas, treina indígenas em habilidades úteis que permitirão que suas vilas permaneçam autônomas ${ }^{12}$. O Cideci não oferece diplomas de graduação, nem é certificado pelo governo mexicano para fazê-lo. Seus líderes argumentam que os diplomas proporcionam a concorrência no mercado educacional, ou seja, os diplomas mercantilizam a educação. Eles preferem, ao invés disso, oferecer treinamento em habilidades como conserto de carros e eletrônicos, que são úteis para garantir que os jovens indígenas encontrem emprego em suas comunidades. A remercantilização é um foco somente nos mercados locais. Por exemplo, a Itanoni Tortilleria em Oaxaca, no México, usa milho local para suas tortilhas, e exige a proibição do milho transgênico. Os plantadores de soja da Bolívia organizam cooperativas para evitar, de maneira semelhante, o uso de soja transgênica ${ }^{13}$. Ao invés de depender do comércio global ou até mesmo do regional, o esforço aqui é para inserir a produção e o comércio nas localidades, de forma que a renda oriunda das trocas permaneça dentro delas.

Porém, o que tais respostas ao neoliberalismo nos dizem acerca da resposta aos desastres? Solnit (2009) descreve as formas de solidariedade que surgem durante momentos de desastre. "Não há dinheiro no que é apropriadamente chamado de livre associação... mas, em desastres, as pessoas se unem e, embora alguns temam essa união como uma multidão violenta, muitos a valorizam como uma experiência de uma sociedade civil que é próxima o suficiente do paraíso (9). Por exemplo, após o furação Katrina, viu-se a ONG Common Ground oferecer uma variedade de serviços voluntários às pessoas afetadas. A organização tinha "métodos extremamente informais" que "permitiam o improviso nas circunstâncias

${ }^{12}$ Baseado em dados coletados durante minha visita e minhas entrevistas, 16 de fevereiro de 2009.
${ }^{13} \mathrm{https}$ / / nacla.org/node/5878 
que se alteravam constantemente" (292). Um de seus voluntários relembra: " 'a Cruz Vermelha tinha cem armazéns por toda parte e seu material estava ficava lá, esperando... nós fizemos amizade com alguns trabalhadores da Cruz Vermelha e dissemos: 'Vamos, precisamos trazer nossos caminhões para cá'... Nós tínhamos uma rede de pessoas comuns trabalhando por todo o Golfo...Somos uma rede de pessoas que agora sabe o que fazer se uma tempestade ocorrer. E todos chamaremos uns aos outros" “ (292-293).

De maneira semelhante, o campo de ajuda humanitária haitiano administrado pela J/P Haitian Relief Organization atraiu atenção favorável da mídia (certamente, devido, em parte, ao fato de ter sido cofundada pelo ator de Hollywood Sean Penn). As reportagens da mídia notavam o contraste em relação a outros campos de ajuda humanitária, em termos de um esforço para reduzir a desigualdade entre quem ajuda e quem recebe ajuda, e para fortalecer a comunidade local. "O pensamento por trás da abordagem de Penn não diz respeito apenas a gastar dinheiro de maneira sábia. Ele também reflete um desejo, surpreendentemente raro no setor de ajuda humanitária, de ser visto como algo que aborda iguais pelas pessoas que ele ajuda. As agências tradicionais podem cair de paraquedas em zonas de desastres com entregas de ajuda, e, em seguida, desaparecer por dias..." Um homem entrevistado declara: “ "Não somos uma força colonizadora. Dormimos em tendas, assim como eles. Não moramos em casas a milhas de distância. Esse tipo de coisa faz uma grande diferença. Significa que entendemos o lugar, e podemos tomar melhores decisões por causa disso.' "14 De maneira semelhante, Misoczky (2010) descreve a resposta do Estado brasileiro à crise do Haiti em termos de um esforço consciente de devolver o poder às comunidades locais, de forma que os usuários dos serviços de saúde tivessem mais controle e voz nesses serviços de ajuda.

Por meio dessas rotas diversas, a capacidade comunitária e a autonomia local são fortalecidas. A resposta a desastres requer não apenas auxílio vindo de fora (seja do Estado ou ajuda externa), canalizado através de organizações formalizadas incluindo as ONGs, mas crucialmente o envolvimento e a capacidade de organizações comunitárias locais. É no nível das famílias que respondem ao desastre, dentro de suas localidades, que o processo de reconstrução pode acontecer. Portanto, ajuda humanitária não é apenas oferecer comida e água, não apenas reconstruir clínicas e escolas, mas restaurar os laços sociais dentro das localidades.

Tal esforço exigirá que os atores externos sejam mais sensíveis e respeitosos com a experiência e sabedoria locais. Isso é especialmente importante na gestão da ajuda. São as pessoas dentro de uma localidade que sabem como repartir e medir a ajuda, para onde direcioná-la, e ${ }^{14}$ http://www.independent.co.uk/news/world/americas/hollywood-star-shows-how-aid-can-help-haiti-
2023810.html 
quando. Mas esta não é uma exortação para se depender de habitantes simbólicos. Ao invés disso, é uma convocação para se inserir conhecimento especializado nas localidades, para envolver os destinatários da ajuda nas decisões que os afetam, estimular as localidades a estabelecer organizações comunitárias responsáveis que possam representá-los e protegê-los adequadamente. A ajuda humanitária efetiva requer não apenas um conhecimento especializado desconexo, mas essas habilidades contextuais locais.

\section{Conclusão}

O gerencialismo está associado a uma expectativa de progresso social, por meio de um maior controle do mundo natural, dos seres humanos e da organização de "pessoas e coisas a fim de que metas coletivas acordadas sejam alcançadas" (Parker, 2002 p. 4). O desejo de controlar, e a esperança de que tal controle fosse possível - de seres humanos, da natureza, da sociedade - origina-se no impulso do Iluminismo, a expectativa de que a racionalidade instrumental pudesse ser identificada, e seus métodos usados para elaborar formas de controle. O gerencialismo como ideologia de conhecimento especializado está intimamente ligado a essa esperança do Iluminismo. Nesse sentido, o gerencialismo (sob vários disfarces) está intimamente ligado a outros projetos, de extensão colonial

de territórios e a exploração de seus recursos (Dussel 2006), regimes de governança que gradualmente ampliam formas de vigilância e autodisciplina até mesmo a esfera íntima da família, e, obviamente, a internalização de normas de mercado para julgar todas as formas da vida social.

Comecei este trabalho lembrando o terremoto que destruiu Santiago do Chile em 1647. Aquele terremoto premeditou um dos mais notórios e infames desastres do século seguinte, na história ocidental, o terremoto de Lisboa em 1755. Espantado com a voracidade do evento, e com a sua brutal repetição (dois tremores secundários e um tsunami seguiram-se ao tremor principal), e incapaz de explicá-lo como intenção divina, o filósofo Voltaire declarou, em uma indicação, que a vida inerentemente não tinha significado. Contudo, em resposta, Rousseau argumentou que o terremoto foi moldado socialmente, que o seu impacto foi agravado pelo modo como a sociedade estava projetada à época, por exemplo, a maneira como os prédios da cidade estavam localizados (Shrady, 2008). É nesse diálogo de três séculos passados que teremos que, em última instância, situar a discussão da prática de gestão. Os desastres contemporâneos e as repostas são uma longa conversa ecoada, na linha sempre em mudança entre agência e casualidade, para se localizar práticas de gestão que melhor respondam a desastres sociais, ao mesmo tempo em que evitam os preconceitos que os agravam. 


\section{Referências}

CLARKE, Lee. Worst cases: Terror and catastrophe in the popular imagination. Chicago: University of Chicago, 2005.

DESMARAIS, Annette Aurelie. La vía campesina: Globalization and the power of peasants. London: Pluto, 2007.

DUSSEL, Enrique. (com Eduardo Ibarra-Colado). Globalization, Organization and the Ethics of Liberation. Organization, v. 13, n. 4, p. 489-508, 2006.

DUSSEL, Enrique. Twenty theses on politics. Durham, North Carolina: Duke University, 2008

ENTEMAN, Willard F. Managerialism: The emergence of a new ideology. Madison: University of Wisconsin, 1993.

GLEDHILL, John. Neoliberalism. In: D. NUGENT; J. VINCENT (Eds.) A companion to the anthropology of politics. London: Blackwell, 2004, p. 332- 348.

RODRÍGUEZ, Havidán; BARNSHAW, John. The social construction of disasters: From heat waves to worst case scenarios. Contemporary Sociology, v. 35, n. 3, p. 218-233, 2006.

HARVEY, David. A brief history of neoliberalism. Oxford: Oxford University, 2007.

KLEIN, Naomi. The Rise of Disaster Capitalism. The Nation, May 2, 2005.

KLINENBERG, Eric. Heat wave: A social autopsy of disaster in Chicago. Chicago: University of Chicago Press, 2002.

KOTHARI, Uma. Authority and expertise: The professionalisation of international development and the ordering of dissent. Antipode, v. 37, n. 3, p. 425-446, 2005.

MOTTA, Sara. Venezuela: reinventing social democracy from below? In: LIEVESLEY, G.; LUDLAM, S. (org.), Reclaiming Latin America: experiments in radical social democracy. London: Zed Books, 2009, p. 7590. 
MIROWSKI, Philip. Posfácio: Defining neoliberalism. In: MIROWSKI; PLEHWE (org.) The Road from Mont Pèlerin: The Making of the Neoliberal Thought Collective. Cambridge, Mass: Harvard University, 2009.

MISOCZKY, Maria Ceci. Na contracorrente do capitalismo do desastre: a cooperação Brasil-Cuba-Haiti para o fortalecimento do Sistema de Saúde Haitiano. 2010. Artigo não publicado.

NERUDA, Pablo. Canto General. Traduzido por Jack Schmitt. Los Angeles: University of California, 1991.

OXHORN, P. Citizenship as consumption or citizenship as agency? The challenge for civil society in Latin America. In: JAMES, H. (org.), Civil society, religion and global governance: Paradigms of power and persuasion. London: Routledge, 2007, p. 100-129.

PARKER, M. Against management: Organisation in the age of managerialism. Cambridge: Polity, 2002.

ROBERTS, Susan M.; JONES, John P.; FROHLING, Oliver. NGOs and the Globalization of Managerialism: A Research Framework. World Development, v. 33, n. 11, p. 1845-1864, 2005.

SADER, E. The weakest link? Neoliberalism in Latin America. New Left Review, v. 52, p. 5-31, 2008.

SCHULLER, Mark. Deconstructing the disaster after the disaster: Conceptualizing disaster capitalism. In: N. GUNEWARDENA; M. SCHULLER, Mark (org.) Capitalizing on catastrophe: Neoliberal strategies in disaster reconstruction. Lanham: Altamira, 2008, p. 17-28.

SHRADY, Nicholas. The last day: Wrath, ruin, and reason in the Great Lisbon Earthquake of 1755. New York: Viking, 2008.

SRINIVAS, Nidhi. Against NGOs? A critical perspective on nongovernmental action. Non-Profit and Voluntary Sector Quarterly, v. 38, n. 4, p. 614-626, 2009.

SRINIVAS, Nidhi. The phenomenon of "NGOs": Perspectives from Latin America. Critical Perspectives of International Business, v. 6, n. 2/3, p. 116-127, 2010.

TIERNEY, Kathleen; BEVC, Christine; KULIGOWSKI, Erica. Metaphors matter: Disaster myths, media frames, and their consequences in Hurricane Katrina. The ANNALS of the American Academy of Political and Social Science, v. 604, n. 1, p. 57-81, 2006. 
TIERNEY, Kathleen J. From the margins to the mainstream?

Disaster research at the crossroads. Annual Review of Sociology, v. 33, p. 503-525, 2007.

TURNER, Rachel. Neo-liberal ideology: History, concepts and policies. Edinburgh: Edinburgh University, 2008.

VELOSO, Caetano; GILBERTO, Gil. Tropicália 2. Nonesuch, 1994.

Von KLEIST, Heinrich. Selected writings. (Traduzido por David

Constantine). London: Hackett, 2004. 